\title{
Policy translation for early childhood education and care: the Growing Up in New Zealand approach
}

\author{
Amy L. Bird ${ }^{1,2,3^{*}}$, Polly E. Atatoa Carr ${ }^{1,2,4}$, Elaine Reese ${ }^{1,2,5}$ and Susan M. B. Morton ${ }^{1,2}$
}

\footnotetext{
*Correspondence:

a.bird@auckland.ac.nz

${ }^{2}$ Growing Up in New

Zealand, The University

of Auckland, Tamaki Campus,

261 Morrin Road, St Johns,

Auckland 1072, New Zealand

Full list of author information

is available at the end of the article
}

\begin{abstract}
Longitudinal cohort studies have significant potential to inform policy across a range of child and family areas, including early childhood education and care. Here we describe the relationship between policy-makers and New Zealand's contemporary pre-birth cohort study. We outline a model for policy interaction that highlights the relationship between Growing Up and policy across study design, implementation and analysis. We then describe key policy-relevant questions in the early childhood education and care area that Growing Up has addressed when children were age 2. We used parent-report data for 6242 children to consider: whether socio-economic factors and ethnicity are related to the type, amount and quality of care children receive, and changes in this care across the early years; whether families are intending to utilise '20 Hours ECE' when their children reach age 3, and if not, why not; and whether differences in intentions to use '20 Hours ECE' are based on socio-economic factors, ethnicity and the type of childcare children are receiving at age 2 . Results indicated clear differences in nonparental care at age 2 as a function of maternal ethnicity, income, area deprivation and household structure. Several child care proxy quality indicators were lower for children of Māori, Pacific and Asian mothers compared with children of European mothers, and for children living in higher deprivation areas. While $88 \%$ of mothers were intending to utilise the Government's '20 Hours ECE' funding, Asian and Pacific mothers and mothers whose children were cared for by family members were less likely. These findings highlight the importance of continued policy efforts to reduce socio-economic and ethnic disparities in education and care during the preschool years.
\end{abstract}

Keywords: Early Childhood Education (ECE), Policy, Longitudinal cohort research

\section{Background}

The past two decades have seen increasing recognition about the importance and potential of large longitudinal cohort studies, not only for informing our understanding of child development and evidence-based interventions, but also for informing the development and evaluation of government policy and programmes for children and families. In New Zealand, our diverse contemporary longitudinal birth cohort was developed with the explicit intent to provide evidence to inform the policy approach (Morton et al. 2013; Morton, Ramke et al. 2015). This paper will focus on the approach to policy 
translation utilised and the relevance of findings from Growing Up in New Zealand for early childhood care and education (ECE).

\section{Growing Up in New Zealand's policy relationship}

Research and science is widely recognised as integral to policy development. Policy, however, is a process. The degree to which research feeds into policy definition, formulation, decision making, implementation or evaluation varies widely across countries, policy issues and particular governments or political structures. Several large cohort studies of child health and development have been developed in close alignment with government in an attempt to more closely align science and policy translation. Growing Up in New Zealand developed from a government-led call for proposals for a longitudinal cohort study and has to date secured government funding for the bulk of core data collection costs.

Government recognition of the value of investment in this longitudinal cohort study is built upon the interaction between Growing Up in New Zealand and those working in policy, across all levels of the research programme. Through the design and development phase of Growing Up in New Zealand, key relationships developed between the Growing Up in New Zealand researchers and research process, and those working in education policy development-particularly senior advisors at the Ministry of Education. These continue to be formalised via a consultation and data reporting process, with examples of activities that are involved in data analysis and dissemination shown in Fig. 1.

The policy interaction process has evolved over time, but the Growing Up in New Zealand Policy Forum has remained an integral mechanism for the communication of ideas between researchers and policy-makers. Aside from the overarching design of the longitudinal study, policy-level involvement is key at each phase. For example, early in the planning process for each data collection wave a face-to-face workshop with the Policy Forum is organised. This group involves senior representatives from all Government

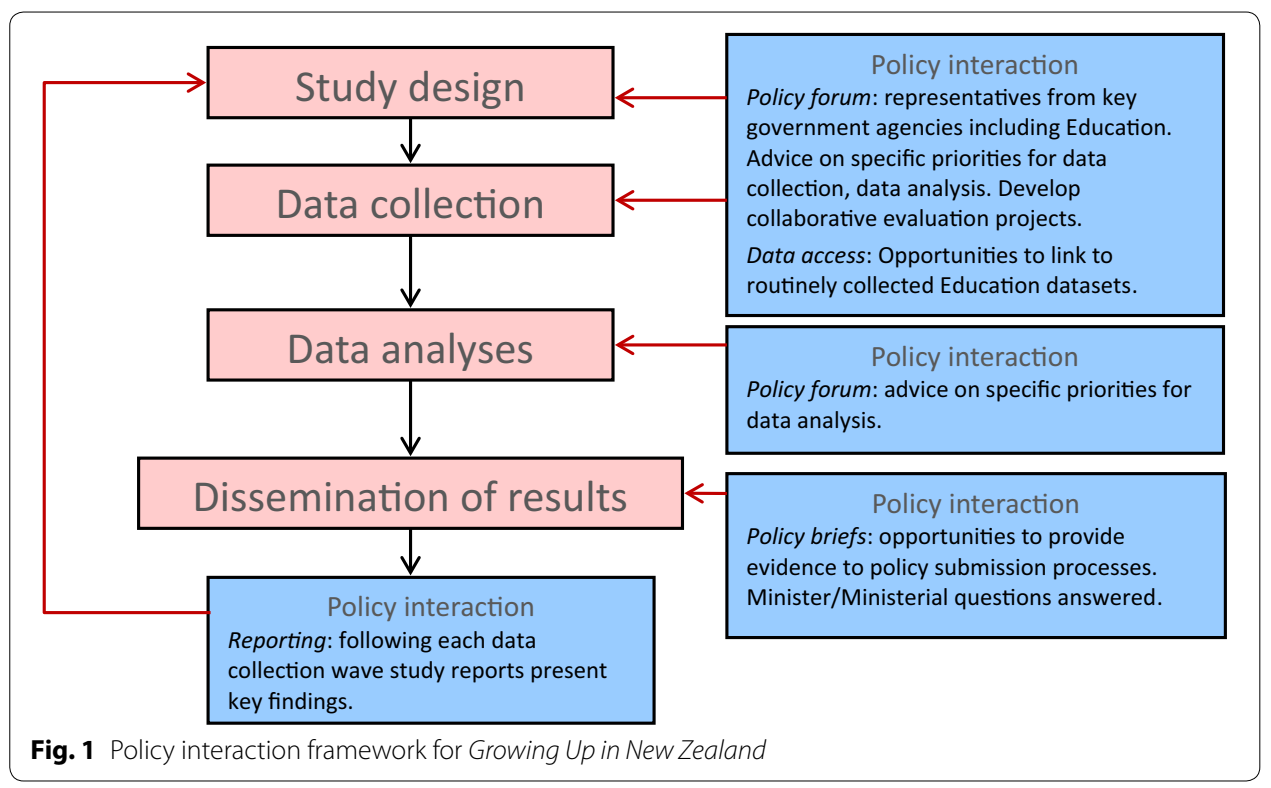


Ministries as well as other policy agencies (such as the Office of the Children's Commission, Housing New Zealand, etc.).

Growing Up in New Zealand is an inter-disciplinary study encompassing six key domains: education, health and well-being, psychosocial and cognitive development, societal context, family and whānau (the indigenous Māori language word for the concept of family), and culture and identity (Morton et al. 2013). Policy Forum therefore typically involves approximately 20-30 government policy representatives, including those with an education focus. Education sector members on Policy Forum also provide advice on areas of data collection that may sit outside education services, but have an impact on educational outcomes. Where a Policy Forum workshop is focused on a specific data collection wave, policy-makers are asked to share their areas of interest and construct data collection priorities, within the overarching longitudinal view. This planning phase also involves interaction with Growing Up's Scientific Advisory Panels and other expert researchers. Once a draft set of tools and questions has been developed, further Policy Forum workshops are organised. These help ensure that initial drafts of data collection methodology best reflect the identified policy priorities, and that a balance can be achieved between participant burden, the need to gather repeat measures, stage of child development and the use of robust measures. Depending on the time frame, feedback from specific ministries is often also sought in the process of refining the data collection wave. For example, Policy Forum activities with a focus on the development of the $4 \frac{1}{2}$ year Data Collection Wave for Growing Up in New Zealand involved three workshops and meetings with individual members of the Ministries of Health, Education and Social Development between April 2012 and March 2013. Constructs that were prioritised by the Ministry of Education Policy Forum members, and other key Ministry of Education advisors over this process included the following: updated early childhood education (ECE) service participation information (choice, availability, utilisation, formal and informal care); service quality; parental involvement in ECE; understanding what children do if they are not at ECE; understanding the social, economic, family and cultural associations with ECE attendance; measuring the nature of preparation for formal schooling; parental beliefs and expectations around education; cognition; and the quality of the parent-child relationship.

As indicated in Fig. 1, for each data collection and throughout the process of developing study outputs, input is again sought from Policy Forum in the data analysis phase. Broad reports are typically produced following each face-to-face data collection wave. For these reports, Policy Forum workshops are again organised in order to prioritise the specific focus of a report (such as those published on potential indictors of child vulnerability and the frequency of residential mobility (Morton et al. 2014a, b, 2015). In addition to broad reports, specific Policy Briefs are developed also in collaboration with policy agencies to ensure that policy-relevant questions are addressed in analyses. Further, senior policy agency members (as well as Ministers) can (and do) make specific requests for analyses. Examples of Policy Briefs and specific analyses conducted include those on the use of the indigenous language (te reo Mãori) in early childhood and arrangements for parental leave (Growing Up in New Zealand 2014, 2015).

The importance of early education and child care to child development is reflected in Growing Up's overall study design, with education being one of the six key domains 
(Morton et al. 2013). However, the detailed design of the constructs and tools used to measure lifecourse development crosses over each domain and interacts with key policy documents in New Zealand. An example of this specific interaction is shown in Table 1 where the strands and levels of learning of the New Zealand Ministry of Education's early childhood curriculum policy statement (Carr and May 1993) are depicted along with their associated domain(s) of measurement within the longitudinal study.

\section{New Zealand's early childhood education and care policy environment}

New Zealand has a diverse environment for the provision of early childhood education and care (ECE) in the first few years of life, prior to the attendance of each child at formal primary school (typically at 5 years of age) (see Table 2). Many forms of ECE are regulated and reviewed by New Zealand's Education Review Office (ERO), including ECE centres, Kindergarten, Kohanga Reo, Pacific Island child care centres, Playcentre and creches (e.g. in community centres, gyms). Home-based care organisations are not regulated by ERO but have their own internal systems of review by trained teachers. Many nannies in New Zealand have some form of child care qualification but there are no exact data on this. Costs vary across regions, although per hour child care costs are typically highest for nanny care, followed by centre-based care and home-based care.

\section{Table 1 Alignment between Te Whariki and Growing Up in New Zealand design}

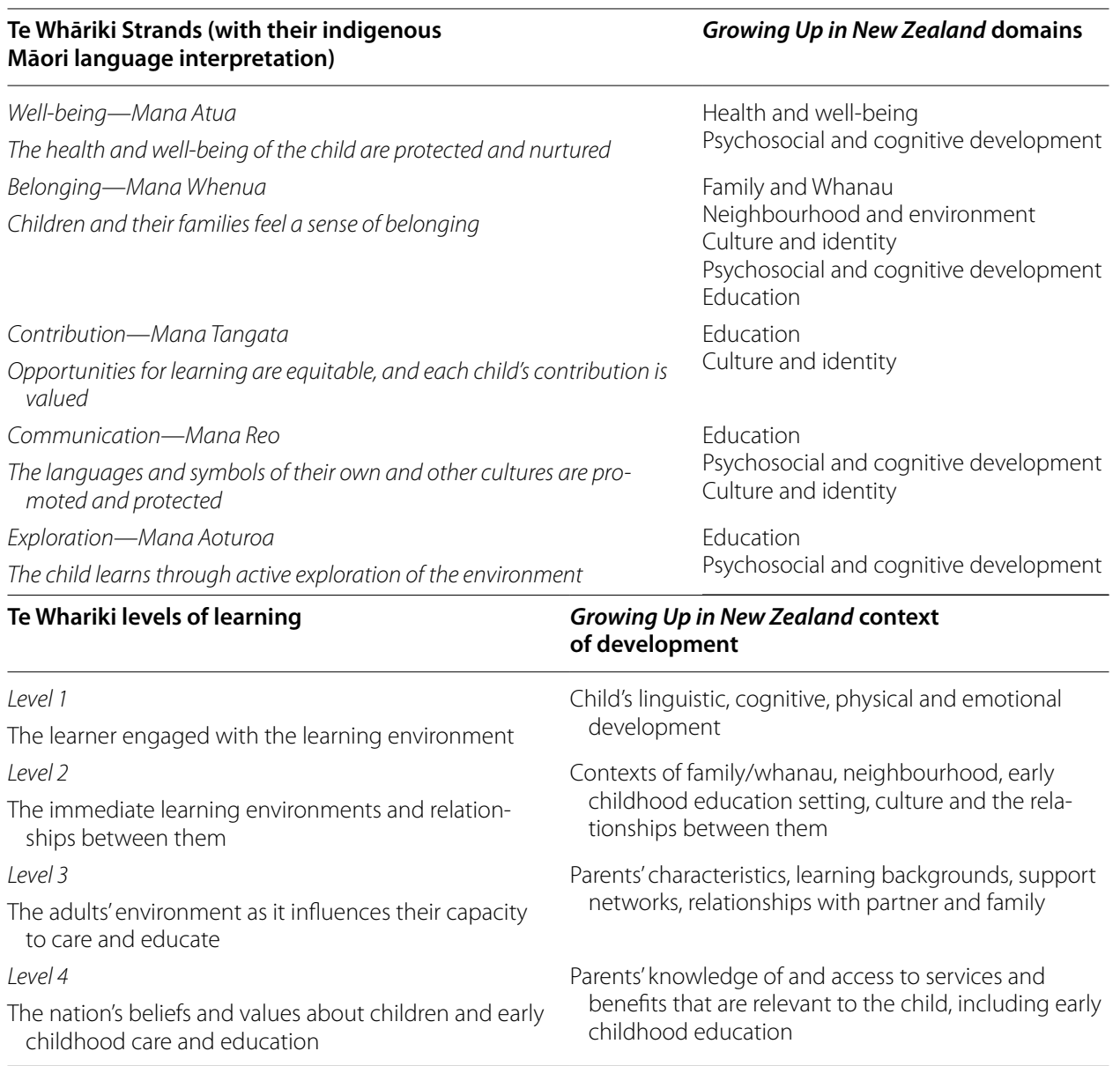


Table 2 New Zealand Early Childhood Care and Education (Bushouse 2008; ERO 2007)

\begin{tabular}{|c|c|}
\hline Early child care & Characteristics \\
\hline Early education and care centre ${ }^{a}$ & $\begin{array}{l}0 \text { - to } 5 \text {-year-olds } \\
\text { Private or business owned } \\
\text { Traditionally used by working parents, however since the introduction of } \\
\text { '20 Hours ECE' more widely used for shorter days or sessions }\end{array}$ \\
\hline Kindergarten & $\begin{array}{l}\text { Attended by 3- to 4-year-olds (licenced for children over } 2 \text { years) } \\
\text { Traditionally morning or afternoon sessions; more recently most offer } \\
\text { school length days to optimise'20 Hours ECE' } \\
\text { Do not charge fees: payment by donation, typically lower costs. Admin- } \\
\text { istered by charitable associations; long history of government funding } \\
\text { and partnership }\end{array}$ \\
\hline Kohanga Reo & $\begin{array}{l}\text { Māori-led childcare with the goal to preserve Te Reo (Māori language) } \\
\text { and Māori culture, and to empower Māori whanau } \\
\text { Graduates (Kaiako) of a 3-year diploma-Whakapakari Tohu-allow } \\
\text { Kohanga Reo to qualify as 'teacher-led'for' } 20 \text { Hours ECE; however, } \\
\text { historically this was not sufficient for teacher registration and higher } \\
\text { funding rates } \\
\text { Declining rolls from a peak in 1994/1995; eligible for '20 Hours ECE' from } \\
2010\end{array}$ \\
\hline Pacific Islands early childhood centre & $\begin{array}{l}\text { Pacific-led childcare with the goal of passing on Pacific language and } \\
\text { culture; may focus on one or several Pacific cultures, and may include a } \\
\text { Christian faith component }\end{array}$ \\
\hline Home-based care & $\begin{array}{l}\text { Home-based educator providing care for children in the home; super- } \\
\text { vised by a registered teacher } \\
\text { An increasing sector in NZ, there are several large organisations (e.g. } \\
\text { PORSE, Barnados) }\end{array}$ \\
\hline Nanny & $\begin{array}{l}\text { Private in-home individual care } \\
\text { Nannies in New Zealand may have formal qualifications or not, and may } \\
\text { be found individually or through agencies } \\
\text { Au pairs or nannies may also live in the home }\end{array}$ \\
\hline Playcentre ${ }^{b}$ & $\begin{array}{l}\text { Active parent involvement: cooperatively administered and staffed by } \\
\text { parents and Playcentre Association } \\
\text { Sessional programmes for children from } 0 \text { to } 5 \text { years } \\
\text { Declining rolls; eligible for ' } 20 \text { Hours ECE' from } 2010\end{array}$ \\
\hline Playgroup & $\begin{array}{l}\text { Organised groups where parents meet together with their children } \\
\text { Shorter sessions, focused on play programmes; typically unlicenced }\end{array}$ \\
\hline
\end{tabular}

a Correspondence School provides early childhood education for children who may live too far from other ECE providers. Together with Hospital ECEs, these are the only Government-run ECE providers in New Zealand

b Because we were interested in non-parental care, Playcentre and Playgroup attendance were not assessed

The 1980s and 1990s saw significant change in the New Zealand ECE sector with an emphasis on improved training of the ECE workforce, development of an ECE teacher professional body and code of ethics, and ECE curriculum development: all contributed to an increasingly professional and qualified teacher workforce (Dalli 2010). These decades also laid the foundations for policy and funding changes in the early 2000s focused on increasing access to high-quality ECE for all children. In 2002, the Ministry of Education released a Strategic Plan with three 10-year goals: to increase participation in early childhood services; to improve the quality of ECE by increasing access to qualified teachers (Manning et al. 2014) and to improve sector collaboration. Between 2000 and 2008, government spending on ECE doubled. In 2007, New Zealand's Labour-led government introduced a '20 Hours free' policy as a key component of this strategic plan. While a range of community and private services are eligible, they must be 'teacher-led' to qualify for this additional funding (see Table 2). Although opting into '20 Hours free' was an individual and service choice, within a year of policy implementation $76 \%$ of services and $86 \%$ of 3- and 4-year-olds were utilising this funding (Bushouse 2008). 
A change to a National-led government in 2008 signalled several changes to the ECE policy focus. Specifically, government signalled a targeted focus on increasing ECE participation for at-risk children. Indigenous Māori children and children that identify within Pacific Island ethnic groupings in NZ have traditionally lower rates of ECE participation, and an achievement gap in higher education and occupational status is evident from the first years of schooling (Bishop et al. 2009; Ministry of Education 2014a). The now-titled '20 Hours ECE' policy reduced the required ratios for qualified teachers (from a goal of 100 to $80 \%$ for 2- to 5 -year-olds and $50 \%$ for under 2 years) and extended eligibility to parent- and community-led services such as Playcentres and Kohanga Reo (indigenous Māori language-focused ECE). There is ongoing debate, however, about differences in funding, quality and access to centre-based, teacher-led ECE compared with community- or family-based care (McLachlan 2011). In addition to '20 Hours ECE', the NZ government also provides partial subsidisation for children aged between 0 and 5 years attending licenced ECE services for up to $30 \mathrm{~h}$ per week: the ECE Funding Subsidy.

This paper focuses on the data analysis component of policy interaction within the Growing Up in New Zealand study and considers several key questions of relevance for New Zealand's ECE policy. Focusing on data collected when the Growing Up cohort children were two years old and highlighting children's participation in ECE, associations between ECE participation and ethnicity and a range of socio-demographic variables, and parents' intentions to utilise '20 Hours free' ECE allows demonstration of the response of Growing Up in New Zealand data analysis to a number of policy-relevant questions as described in Box 1. Overarching these specific areas of policy utility is the alignment between Growing Up in New Zealand data delivery and the New Zealand Government's priorities to address disparities, raise achievement and improve equity (Ministry of Education Statement of Intent).

Box 1. Policy-relevant questions for Growing Up in New Zealand children's use of ECE at age 2 years

1. Are socio-economic factors and ethnicity related to the type of care children receive, and changes in this care across the early years?

2. Are socio-economic factors and ethnicity related to the amount and quality of child care children receive?

3. Are families intending to utilise ' 20 hours ECE' when their children reach age 3 ? If not, why not?

4. Are there differences in intentions to use '20 Hours ECE' based on socio-economic factors, ethnicity and the type of childcare children are receiving at age 2 ? 


\section{Methods}

\section{Participants}

Participants were members of New Zealand's longitudinal pre-birth cohort study: Growing Up in New Zealand. Women were recruited during pregnancy from a geographically defined region of New Zealand chosen for its population diversity (Morton et al. 2013). All pregnant women who resided within this region and who had an estimated due date between 25th April 2009 and 25th March 2010 were eligible. A multi-faceted recruitment strategy was utilised with the goal of recruiting a sample broadly generalisable to the contemporary New Zealand national birth cohort (Morton et al. 2012). Alignment of the enrolled cohort with the national birth cohort was confirmed (Morton et al. 2015). Ethical approval was obtained from the Ministry of Health Ethics Committee. Written informed consent was obtained from all participating women.

The current analyses are based on responses from 6242 (99\% of the 2-year cohort) of the 6327 ( $92 \%$ of the original cohort) mothers interviewed when their children were 2 years old.

\section{Procedure}

The two-year computer-assisted interview was conducted face to face in the child's home. Mothers were asked a range of questions across multiple domains (health, psychosocial and cognitive development, family and whanau, education, culture and identity, and neighbourhood and societal context; see Morton et al. 2013).

\section{Measures}

Non-parental care Mothers were asked a range of questions about non-parental care including type (grouped in centre-based care by a relative, nanny or home-based care ${ }^{1}$ ) and reasons for using current care type. Several questions were also included as proxy self-report indicators of quality: previous changes in care providers; changes in primary carer within the same provider; number of hours of non-parental care; frequency of feedback about child's day and child's development (from $1=$ never to $5=$ daily); frequency of small-group activities (from $1=$ never to $5=$ daily); frequency of trips or outings (from $1=$ never to $5=$ several times a week); number of different dedicated play areas and overall satisfaction with current care provider (from $1=$ very dissatisfied to $5=$ very satisfied). Mothers were also asked whether they intended to utilise ' 20 Hours ECE' when their child turned three and if not, why not.

Socio-demographic measures and ethnicity classification Women were asked a range of standard demographic questions at the antenatal interview. Area-level socio-economic deprivation was measured using the NZ Index of Deprivation (Salmond, Crampton and Atkinson, 2007) and grouped into low deprivation (1-3), medium deprivation (4-7) and high deprivation (8-10). Maternal education was grouped into the following categories based on the highest qualifications: no formal qualifications, secondary school, trade or university qualification. Women were asked to self-prioritise their ethnicity and

\footnotetext{
${ }^{1}$ A list of all child care questions and response options can be found at http://www.growingup.co.nz. Centre-based care was a category based on responses to centre, Kohanga Reo, crèche, Pacific Island child care centre. Family or relative care could be in the child's own home or the family member's home. Nanny care was defined as paid care by a nonrelative within the child's own home. Home-based care was defined as paid care by a non-relative in the other person's home.
} 
responses were grouped into the following categories: European, Mãori, Pacific, Asian and Other. Maternal report of household income was grouped into low $(<$ NZD50,000), medium (NZD50,000-NZD100,000) or high (>NZD100,000). Maternal age was categorised into $<20$ years, $20-29$ years, $30-39$ years and $>40$ years. Maternal reports of household living arrangements were classified into one parent living alone, two parents living together, one or two parents living with extended family and one or two parents living with non-relatives.

\section{Data analysis}

We used descriptive statistics to report parents' reasons for choosing type of child care, and intentions for ' 20 Hours ECE.' We developed logistic regression models to examine associations of socio-demographic variables with type of non-parental care. We also used logistic regression modelling to examine socio-demographic predictors of intentions for ' 20 Hours ECE.' We reported independent associations using adjusted odds ratios (ORs) and $95 \%$ confidence intervals (CIs). We used ANOVAs to examine mean differences in amount of care and parental satisfaction ratings as a function of ethnicity, area deprivation and care type. We used Chi squares to report differences in quality of care, as indexed by the frequency of carer report, trips or outings, small-group activities and number of dedicated play spaces. Analyses were conducted using SAS software (version 9.4, SAS Institute, Cary, NC, US). A two-sided p value of $<0.05$ was considered statistically significant.

\section{Results}

Policy Question 1 Are socio-economic factors and ethnicity related to the type of care children receive, and changes in this care across the early years?

Logistic regression models were created where maternal ethnicity, age, household structure and income, education, child parity and area deprivation predicted the likelihood of children being cared for by centre, extended family, nanny or home-based care; and the likelihood of having four or more changes in care from birth to 2 years (see Table 3). For each type of child care, a dichotomous outcome variable was created (e.g. centre-based care 1 vs no centre-based care 0 ; nanny care 1 vs no nanny care ${ }^{2}$ ). Each socio-demographic predictor variable had multiple levels, and all socio-demographic predictor variables were modelled against each of the child care variables. The reference group for each socio-demographic variable is indicated in the table with an OR of 1. Table 3 highlights similarities and differences in predictors of care type from 9 months (Atatoa-Carret et al. 2016) to 2 years.

Similar to our 9-month findings, European and Māori families are more likely to opt for centre-based care when children are 2 years of age, whereas Asian and Pacific families are more likely to use care by other relatives. By 2 years, Māori, Pacific and Asian families are less likely than European families to use a nanny or home-based care. Children of Māori mothers $(\mathrm{OR}=1.54)$ and first-born children $(\mathrm{OR}=1.73)$ are more likely to experience multiple (4+) changes in childcare before the age of 2 years. Children of a sole parent living alone are almost four times more likely $(\mathrm{OR}=3.76)$ than children of

\footnotetext{
$\overline{2}$ This included only those children who received more than $8 \mathrm{~h}$ of non-parental care, and referred to their main type of care only.
} 
Table 3 Logistic regression models: socio-demographic predictors of child care type at 2 years and number of changes in care type since birth

\begin{tabular}{|c|c|c|c|c|c|}
\hline \multirow{2}{*}{$\begin{array}{l}\text { Antenatal } \\
\text { dependent } \\
\text { variables }\end{array}$} & \multicolumn{4}{|c|}{ 2-year child care type } & \multirow{2}{*}{$\begin{array}{l}>4 \text { changes } \\
\text { in care } \\
\text { since birth OR } \\
(95 \% \mathrm{Cl})\end{array}$} \\
\hline & $\begin{array}{l}\text { Model 1: } \\
\text { Centre OR } \\
(95 \% \mathrm{Cl})\end{array}$ & $\begin{array}{l}\text { Model 2: } \\
\text { Family OR } \\
(95 \% \mathrm{Cl})\end{array}$ & $\begin{array}{l}\text { Model 3: } \\
\text { Nanny OR } \\
(95 \% \mathrm{Cl})\end{array}$ & $\begin{array}{l}\text { Model 4: } \\
\text { Home-based } \\
\text { OR }(95 \% \mathrm{Cl})\end{array}$ & \\
\hline \multicolumn{6}{|l|}{ Ethnicity } \\
\hline European & 1.00 & 1.00 & 1.00 & 1.00 & 1.00 \\
\hline Māori & $\begin{array}{l}2.31(1.67 \\
3.23) \\
p<0.0001\end{array}$ & $0.84(0.54,1.27)$ & $\begin{array}{c}0.32(0.09 \\
0.79) \\
p=0.03\end{array}$ & $\begin{array}{l}0.38(0.21 \\
0.64) \\
p=0.0007\end{array}$ & $\begin{array}{c}1.54(1.03,2.26) \\
p=0.03\end{array}$ \\
\hline Pacific & $1.19(0.84,1.70)$ & $\begin{array}{l}2.19(1.45 \\
3.28) \\
p=0.0002\end{array}$ & $\begin{array}{l}0.14(0.01 \\
0.65) \\
p=0.05\end{array}$ & $\begin{array}{l}0.23(0.09 \\
0.51) \\
p=0.001\end{array}$ & $1.11(0.64,1.85)$ \\
\hline Asian & $\begin{array}{l}0.60(0.46 \\
0.78) \\
p=0.0002\end{array}$ & $\begin{array}{l}3.77(2.77 \\
5.14) \\
p<0.0001\end{array}$ & $\begin{array}{l}0.38(0.16 \\
0.80) \\
p=0.02\end{array}$ & $\begin{array}{l}0.45(0.27 \\
0.72) \\
p=0.002\end{array}$ & $0.86(0.55,1.29)$ \\
\hline Other & $\begin{array}{l}1.90(1.17 \\
3.21) \\
p=0.01\end{array}$ & $\begin{array}{l}0.35(0.11 \\
0.86) \\
p=0.04\end{array}$ & $1.15(0.47,2.46)$ & $\begin{array}{l}0.42(0.16 \\
0.91) \\
p=0.05\end{array}$ & $0.70(0.29,1.44)$ \\
\hline \multicolumn{6}{|l|}{ Area deprivation } \\
\hline Low deprivation & 1.00 & 1.00 & 1.00 & 1.00 & 1.00 \\
\hline Medium & $1.06(0.86,1.30)$ & $1.18(0.87,1.61)$ & $0.74(0.50,1.07)$ & $0.90(0.66,1.22)$ & $0.94(0.70,1.28)$ \\
\hline High deprivation & $1.12(0.88,1.44)$ & $\begin{array}{l}1.44(1.02 \\
2.03) \\
p=0.04\end{array}$ & $\begin{array}{l}0.55(0.30 \\
0.96) \\
p=0.04\end{array}$ & $0.69(0.46,1.03)$ & $0.96(0.67,1.38)$ \\
\hline \multicolumn{6}{|l|}{ Household income } \\
\hline Low & $0.82(0.60,1.11)$ & $1.07(0.72,1.57)$ & $0.50(0.18,1.16)$ & $\begin{array}{l}1.82(1.12 \\
2.92) \\
p=0.01\end{array}$ & $\begin{array}{c}0.42(0.25,0.70) \\
p=0.001\end{array}$ \\
\hline Medium & $0.97(0.79,1.19)$ & $1.15(0.87,1.51)$ & $\begin{array}{l}0.46(0.29 \\
0.72) \\
p=0.001\end{array}$ & $1.31(0.96,1.80)$ & $0.85(0.64,1.14)$ \\
\hline High & 1.00 & 1.00 & 1.00 & 1.00 & 1.00 \\
\hline \multicolumn{6}{|l|}{ Maternal education } \\
\hline $\begin{array}{l}\text { No formal qualifica- } \\
\text { tions }\end{array}$ & $0.80(0.46,1.41)$ & $1.54(0.73,3.03)$ & - & $2.02(0.86,4.31)$ & $0.74(0.27,1.72)$ \\
\hline $\begin{array}{l}\text { Secondary school or } \\
\text { trade }\end{array}$ & $1.04(0.86,1.25)$ & $1.22(0.94,1.57)$ & $\begin{array}{l}0.53(0.34 \\
0.79) \\
p=0.003\end{array}$ & $1.16(0.87,1.55)$ & $0.93(0.70,1.22)$ \\
\hline University & 1.00 & 1.00 & 1.00 & 1.00 & 1.00 \\
\hline \multicolumn{6}{|l|}{ Maternal age (years) } \\
\hline$<20$ & $1.59(0.74,3.73)$ & $0.75(0.27,1.82)$ & - & $0.36(0.10,1.28)$ & $1.20(0.42,2.94)$ \\
\hline $20-29$ & 1.00 & 1.00 & 1.00 & 1.00 & 1.00 \\
\hline $30-39$ & $0.85(0.69,1.05)$ & $1.12(0.86,1.48)$ & $\begin{array}{l}2.39(1.34 \\
4.60) \\
p=0.005\end{array}$ & $1.03(0.75,1.42)$ & $0.91(0.68,1.23)$ \\
\hline$>40$ & $\begin{array}{l}0.48(0.31 \\
0.73) \\
p=0.0007\end{array}$ & $0.54(0.22,1.14)$ & $\begin{array}{l}3.45(1.45 \\
8.16) \\
p=0.005\end{array}$ & $\begin{array}{l}2.37(1.31 \\
4.16) \\
p=0.003\end{array}$ & $0.74(0.34,1.43)$ \\
\hline \multicolumn{6}{|l|}{ Parity } \\
\hline First-child & $1.00(0.83,1.20)$ & $1.12(0.87,1.44)$ & $\begin{array}{l}0.47(0.32 \\
0.69) \\
p=0.0001\end{array}$ & $\begin{array}{l}1.65(1.25 \\
2.20) \\
p=0.0005\end{array}$ & $\begin{array}{c}1.73(1.32,2.26) \\
p<0.0001\end{array}$ \\
\hline $\begin{array}{l}\text { Subsequent child } \\
\text { Household structure }\end{array}$ & 1.00 & 1.00 & 1.00 & 1.00 & 1.00 \\
\hline $\begin{array}{l}\text { One parent living } \\
\text { alone }\end{array}$ & $1.29(0.64,2.81)$ & $0.47(0.11,1.38)$ & $1.14(0.06,6.61)$ & $0.43(0.07,1.52)$ & $\begin{array}{c}3.76(1.48,8.74) \\
p=0.003\end{array}$ \\
\hline
\end{tabular}


Table 3 continued

\begin{tabular}{|c|c|c|c|c|c|}
\hline \multirow{2}{*}{$\begin{array}{l}\text { Antenatal } \\
\text { dependent } \\
\text { variables }\end{array}$} & \multicolumn{4}{|c|}{ 2-year child care type } & \multirow{2}{*}{$\begin{array}{l}>4 \text { changes } \\
\text { in care } \\
\text { since birth OR } \\
(95 \% \mathrm{Cl})\end{array}$} \\
\hline & $\begin{array}{l}\text { Model 1: } \\
\text { Centre OR } \\
(95 \% \mathrm{CI})\end{array}$ & $\begin{array}{l}\text { Model 2: } \\
\text { Family OR } \\
\text { (95\% Cl) }\end{array}$ & $\begin{array}{l}\text { Model 3: } \\
\text { Nanny OR } \\
(95 \% \mathrm{Cl})\end{array}$ & $\begin{array}{l}\text { Model 4: } \\
\text { Home-based } \\
\text { OR }(95 \% \mathrm{Cl})\end{array}$ & \\
\hline Two parents & 1.00 & 1.00 & 1.00 & 1.00 & 1.00 \\
\hline $\begin{array}{l}\text { Parent }(\mathrm{s})+\text { extended } \\
\text { family }\end{array}$ & $\begin{array}{l}0.71(0.56 \\
0.91) \\
p=0.005\end{array}$ & $\begin{array}{l}1.92(1.43 \\
2.55) \\
p<0.0001\end{array}$ & $0.79(0.39,1.47)$ & $0.77(0.50,1.16)$ & $1.12(0.78,1.58)$ \\
\hline $\begin{array}{l}\text { Parent(s) + other } \\
\text { adults }\end{array}$ & $1.02(0.71,1.48)$ & $1.12(0.68,1.77)$ & $0.85(0.29,2.00)$ & $0.90(0.49,1.56)$ & $1.38(0.82,2.23)$ \\
\hline
\end{tabular}

two parents living together to experience multiple changes $(4+)$ in childcare arrangements in the first 2 years of life.

Policy Question 2: Are socio-economic factors and ethnicity related to the amount and quality of child care children receive?

Mean differences were calculated for average hours per week of non-parental care as a function of ethnicity and area deprivation. Figure 2 demonstrates that Pacific $(x=29.1)$ and Asian $(x=30.0)$ mothers used more hours of non-parental care than European $(x=21.4)$ or Māori $(x=26.8)$ mothers. Figure 3 demonstrates that children living in low-deprivation areas received fewer hours of non-parental care per week $(x=22.0)$ than children living in medium-deprivation $(x=23.6)$ or high-deprivation $(x=26.3)$ areas.

Logistic regression models were created where maternal ethnicity, age, household structure and income, education, area deprivation and type of child care predicted proxy quality indicators (see Table 4). Overall, Māori mothers reported that they were less likely to receive daily feedback on their child's day $(\mathrm{OR}=0.51)$, and that their children were less likely to take part in daily small-group activities $(\mathrm{OR}=0.64)$. However, children of Māori mothers were more likely to go on trips or outings at least once per week $(\mathrm{OR}=1.80)$. Pacific mothers were also less likely to receive daily feedback about their child's day $(\mathrm{OR}=0.49)$, and their children were less likely to take part in small-group activities $(\mathrm{OR}=0.55)$. Māori $(\mathrm{OR}=0.66)$, Pacific $(\mathrm{OR}=0.60)$ and Asian $(\mathrm{OR}=0.37)$ mothers were less likely than European mothers to be very satisfied with their child's care.

Compared with mothers from high-income households, mothers with low $(\mathrm{OR}=0.63)$ or medium $(\mathrm{OR}=0.73)$ household incomes were less likely to receive daily feedback on their child's day. Mothers with medium household incomes were less likely to report daily small-group activities $(\mathrm{OR}=0.78)$ and were less satisfied overall with their child's care $(\mathrm{OR}=0.74)$.

The strongest patterns of association were for child care type. Compared with mothers of children in centre-based care, mothers of children cared for by family, a nanny or in home-based care were more likely to receive daily feedback on their child's day and development, more likely to be very satisfied with their child's care, and their children were more likely to go on trips or outings at least once per week and less likely to have 


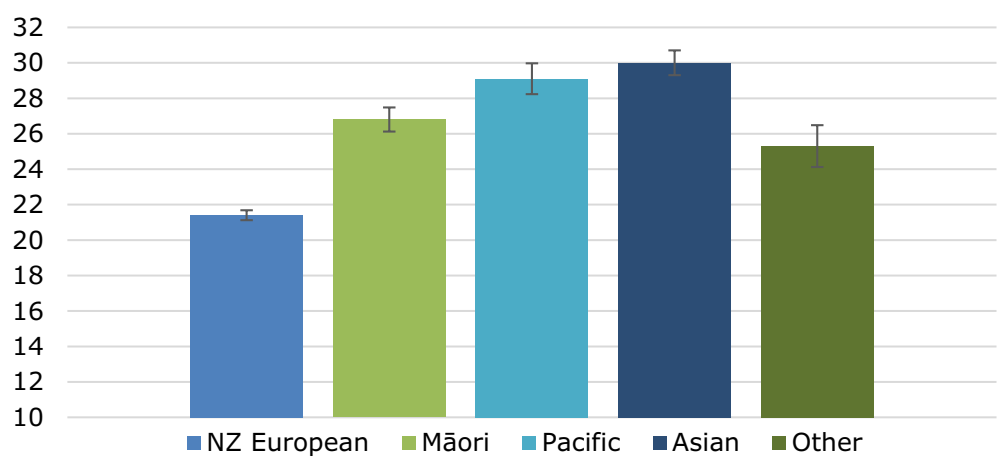

Fig. 2 Differences in mean hours of non-parental care per week by ethnicity

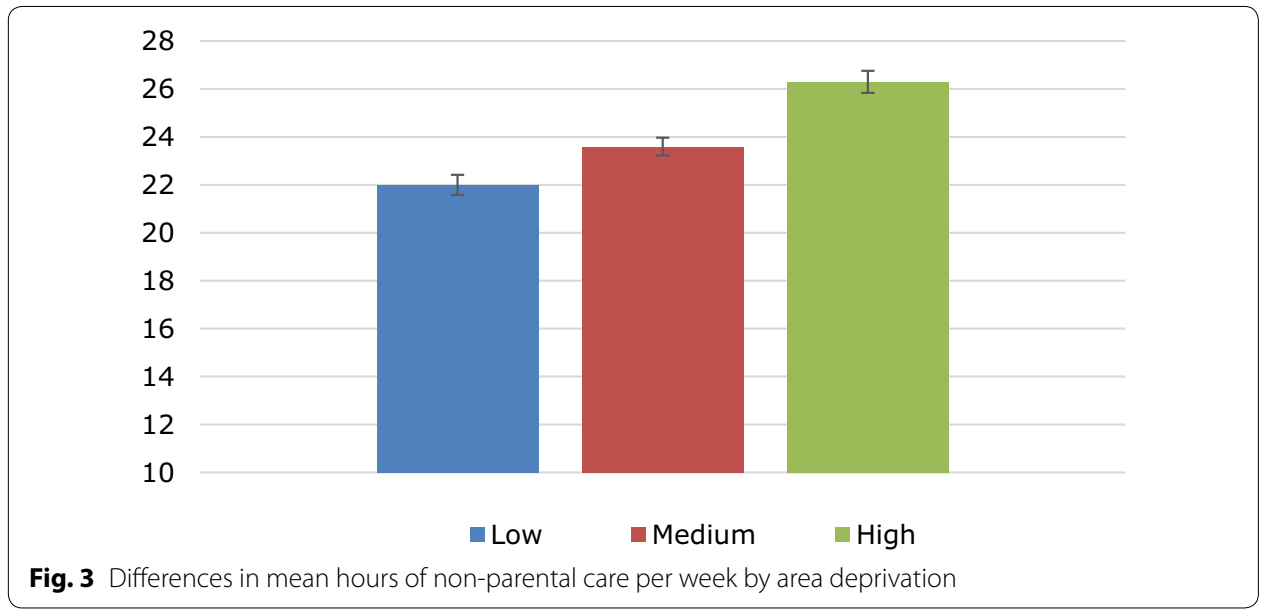

changes in the primary caregiver at childcare. However, children in family, nanny or home-based care were less likely to have daily organised small-group activities.

Policy Question 3 Are families intending to utilise '20 Hours ECE' when their children reach age 3 ? If not, why not?

At the 2-year data collection wave, $5471(88 \%)$ of mothers indicated that they intended to use the '20 Hours ECE' scheme when their children reach age 3; 395 (6 \%) were not intending to and $370(6 \%)$ responded that they did not know. Mothers who indicated that they were not intending to use the scheme were then asked to describe why (Table 5).

Of these reasons, just under half can be considered personal decisions (e.g. not using childcare) or non-modifiable (e.g. living overseas). Almost one-third can be viewed as potentially modifiable factors related to the scheme itself, or the way information is communicated (e.g. cross-over with other government subsidies; lack of information about the policy).

Policy Question 4 Are there differences in intentions to use '20 Hours ECE' based on socio-economic factors, ethnicity and the type of childcare children are receiving at age 2?

Differences in intention to use ' 20 Hours ECE' as a function of socio-demographic factors is shown in Table 6. Logistic regression models were then created to examine these differences. Results indicated that Pacific $(\mathrm{OR}=0.47)$ and Asian $(\mathrm{OR}=0.70)$ mothers 


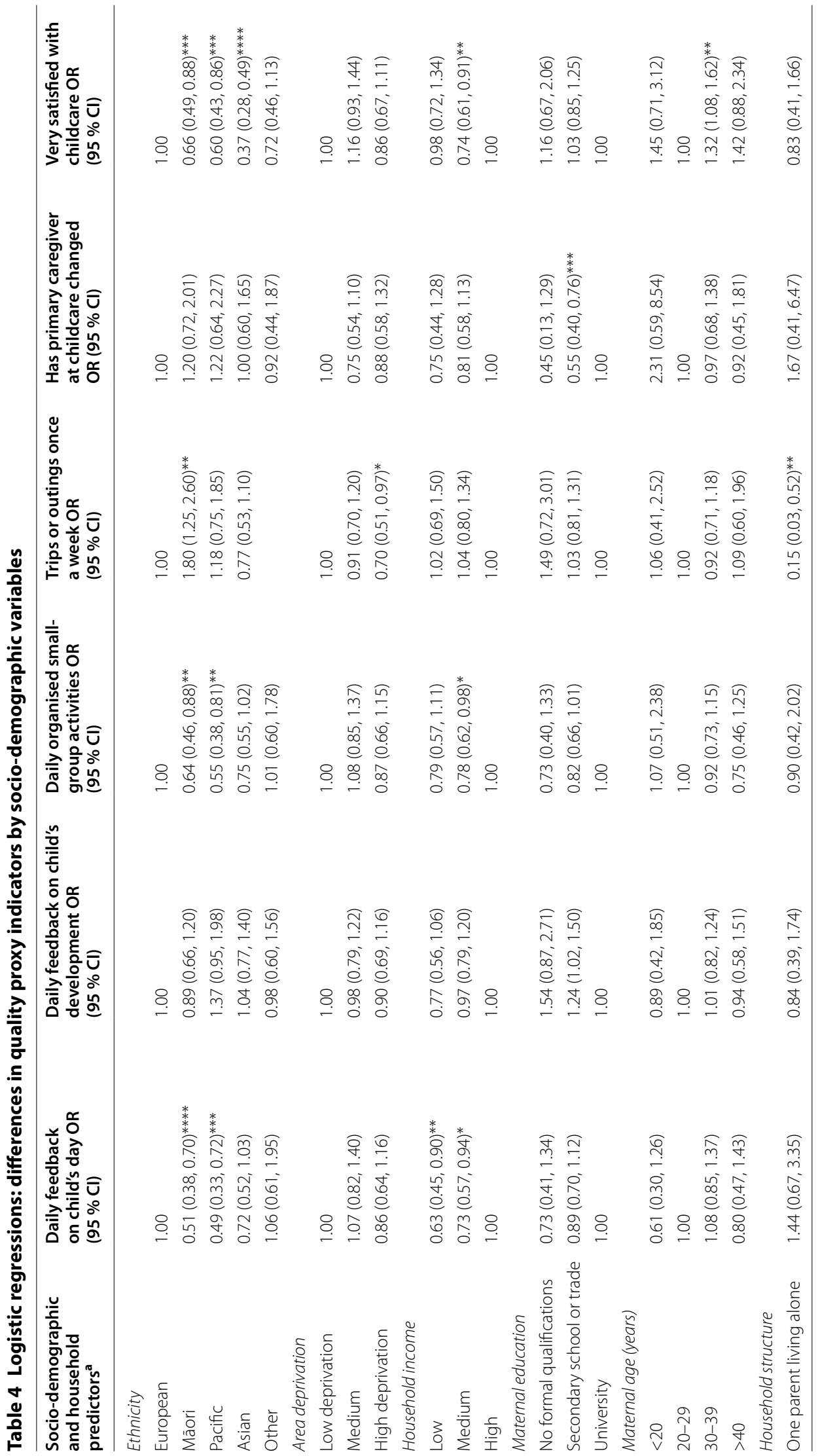




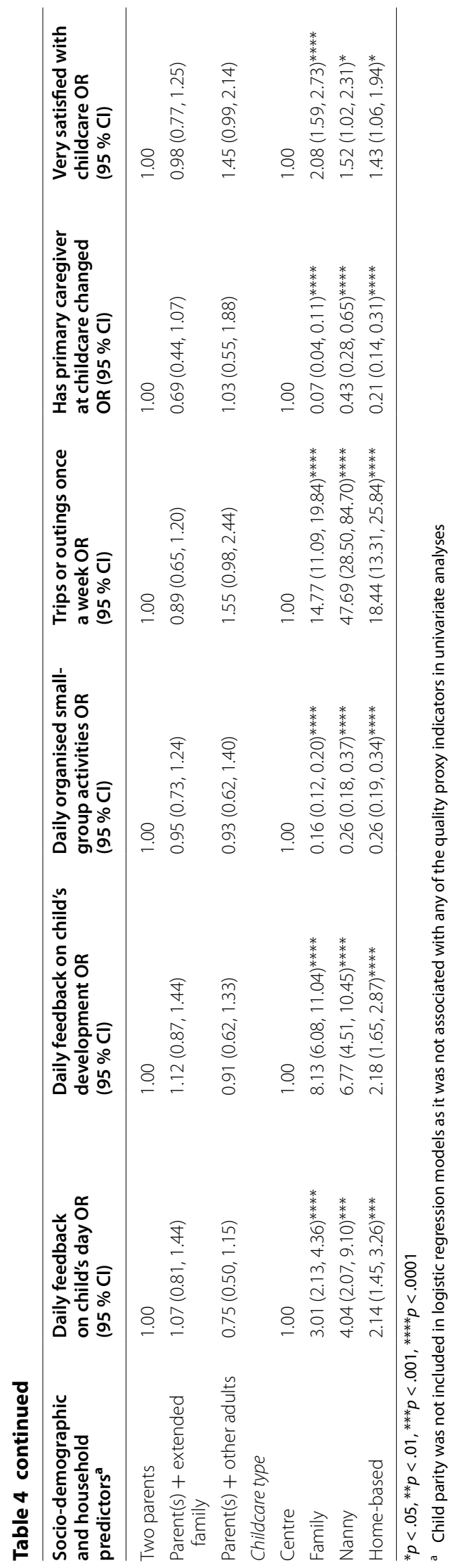


Table 5 Reasons for not intending to use '20 Hours ECE'

\begin{tabular}{lc}
\hline Reason & N (\%) \\
\hline Policy information reasons & $97(2)$ \\
Don't know about scheme or have incorrect information & $17(<1)$ \\
Too difficult to apply & $<10(<1)$ \\
Family did not think that they would be entitled to the scheme because they earned too much & $63(1)$ \\
Access reasons & $15(<1)$ \\
Childcare arrangement does not qualify or has chosen not to be part of the scheme & \\
'20 Hours free' scheme would work out more expensive than their current funding arrangement (e.g. & \\
through other government subsidy) & $53(1)$ \\
Personal/family reasons & $56(1)$ \\
Time in childcare would not benefit child & $69(1)$ \\
Family living overseas & $<10(<1)$ \\
Not using childcare & $<10(<1)$ \\
Family can afford to pay the costs of childcare so felt that they should pay themselves & \\
Other, don't know or preferred not to say &
\end{tabular}

were less likely than European mothers to intend to use '20 Hours ECE'. Lower income families $(\mathrm{OR}=0.51)$, mothers over 40 years of age $(\mathrm{OR}=0.60)$ and mothers of first children $(\mathrm{OR}=0.78)$ were also less likely to intend to use '20 Hours ECE'.

We then considered intention to use ' 20 Hours ECE' by child care type alone. Only mothers of children cared for by family were significantly less likely to intend to use ' 20 Hours ECE' $(\mathrm{OR}=0.32)$.

\section{Discussion}

The New Zealand Ministry of Education has been a key stakeholder for the Growing Up in New Zealand longitudinal study since the development phase of this research. Education is one of the six domains of enquiry for this study and therefore a key component of every data collection wave. Involvement from the Ministry of Education has included funding, governance, development of questionnaire focus and tools, advice on dissemination of results and the provision of policy-relevant information from the research team to the policy advisors. Ongoing collaborations between the New Zealand Ministry of Education and Growing Up in New Zealand, as well as the relationships developed across the policy sectors, are intended to allow effective policy translation.

The findings in this paper also provide integral information for New Zealand ECE policy-makers. NZ's current ECE policy is particularly focused on reducing inequities during early childhood. The size of our sample, as well as its ethnic and socio-economic diversity, allows Growing Up in New Zealand to address these issues.

These results indicate that, as seen when the Growing Up in New Zealand cohort was 9 months of age, the type of non-parental care at age 2 years is strongly related to maternal ethnicity. Centre-based care was a more common choice for European and Māori mothers, family care for Asian and Pacific mothers and nanny and home-based care for European mothers.

We also examined several proxy indicators of child care quality (Manning et al. 2014; Melhuish 2001). Children of Māori mothers, first-born children and children of sole parents were more likely to have multiple changes in care provider between birth 
Table 6 Socio-demographic predictors of intention to use ' 20 Hours ECE'

\begin{tabular}{|c|c|c|}
\hline & $\begin{array}{l}\text { Not intending to use } \\
\text { ' } 20 \text { Hours ECE' } n \text { (row \%) }\end{array}$ & $\begin{array}{l}\text { Intending to use } \\
\text { ' } 20 \text { Hours ECE' OR }(95 \% \mathrm{Cl})\end{array}$ \\
\hline \multicolumn{3}{|l|}{ Ethnicity } \\
\hline European & $3171 / 3474(91)$ & 1.00 \\
\hline Māori & 719/825 (87) & $0.81(0.60,1.10)$ \\
\hline Pacific & 631/823 (77) & $0.47(0.35,0.63)^{* * * *}$ \\
\hline Asian & $731 / 860(85)$ & $0.70(0.53,0.92)^{*}$ \\
\hline Other & 191/219 (87) & $0.86(0.53,1.48)$ \\
\hline \multicolumn{3}{|l|}{ Area deprivation } \\
\hline Low deprivation & $1455 / 1608(90)$ & 1.00 \\
\hline Medium & $2101 / 2336(90)$ & $1.12(0.87,1.44)$ \\
\hline High deprivation & 1899/2273 (84) & $0.84(0.64,1.10)$ \\
\hline \multicolumn{3}{|l|}{ Household income } \\
\hline Low & $881 / 1071(82)$ & $0.51(0.39,0.68)^{* * * *}$ \\
\hline Medium & 1713/1919 (89) & $0.79(0.62,1.00)$ \\
\hline High & $1691 / 1836(92)$ & 1.00 \\
\hline \multicolumn{3}{|l|}{ Maternal education } \\
\hline No formal qualifications & 330/393 (84) & $1.07(0.68,1.71)$ \\
\hline Secondary school or trade & 2862/3322 (86) & $0.94(0.76,1.16)$ \\
\hline University & $2251 / 2486(91)$ & 1.00 \\
\hline \multicolumn{3}{|l|}{ Maternal age } \\
\hline$<20$ years & $216 / 266(81)$ & $1.06(0.63,1.88)$ \\
\hline 20-29 years & 2035/2359 (86) & 1.00 \\
\hline 30-39 years & 2975/3322 (90) & $0.98(0.79,1.21)$ \\
\hline$>40$ years & 231/272 (85) & $0.60(0.40,0.93)^{*}$ \\
\hline \multicolumn{3}{|l|}{ Parity } \\
\hline First-child & $3157 / 3582(88)$ & $0.78(0.64,0.96)^{*}$ \\
\hline Subsequent Child & $2295 / 2630(87)$ & 1.00 \\
\hline \multicolumn{3}{|l|}{ Household structure } \\
\hline One parent living alone & 182/208 (88) & $1.51(0.81,3.08)$ \\
\hline Two parents & $3738 / 4171(90)$ & 1.00 \\
\hline Parent(s) + extended family & $1246 / 1498(83)$ & $0.87(0.69,1.11)$ \\
\hline Parent(s) + other adults & 286/335 (85) & $0.89(0.61,1.34)$ \\
\hline \multicolumn{3}{|l|}{ Child care type } \\
\hline Centre & $1840 / 1950(94)$ & 1.00 \\
\hline Family & 390/464 (84) & $0.32(0.23,0.43)^{* * * *}$ \\
\hline Nanny & 151/163 (93) & $0.75(0.42,1.47)$ \\
\hline Home-based & 280/291 (96) & $1.52(0.85,3.03)$ \\
\hline
\end{tabular}

${ }^{*} p<.05,{ }^{* *} p<.01,{ }^{* * *} p<.001,{ }^{* * * *} p<.0001$

and 2 years of age. Māori and Pacific mothers were less likely to receive daily feedback on their child's day, and their children were less likely to take part in daily organised small-group activities. Māori, Pacific and Asian mothers were less likely than those of European ethnicity to be very satisfied with their child's care. Children living in low- or medium-income households also showed a pattern of reduced ECE quality, according to these indicators. These findings remained when a range of other confounders was controlled for in the analyses, including type of child care. The policy implications of these results relate to the ability of Ministry of Education resources to be targeted to 
address disparity in educational achievement across subpopulation groups in New Zealand (Ministry of Education 2014b). If those children from more deprived households, and our indigenous children, have poorer access to quality ECE and/or are more likely to experience multiple changes in ECE provision within the first few years of life, then we need to pay further attention to the pathways available to provide education of increasing quality and value for all (Sylva et al. 2010).

The specificity of our findings is limited somewhat by our need to group variables. For example, there may be differences in maternal age within our 10-year brackets; and Pacific cultures are a heterogeneous group (although being a key policy target). Similarly, some of the differences in proxy quality indicators are likely to be an inevitable function of care type. For example, children cared for by a nanny, relative or home-based carer were more likely to experience trips or outings at least once a week, and their parents were more likely to receive daily feedback about their child. We may however be comparing 'apples with oranges': a centre may not receive a positive indicator here, yet might have comprehensive discussions once a week with parents and take children once a month to the zoo. Similarly, a nanny might receive a positive indicator on these variables because they have more opportunity for even brief 1:1 daily feedback, and might take the child to the supermarket with them once a week. What represents 'quality care' may differ across care types, but this information may be valuable nevertheless for child carers and policy-makers. Further work with the New Zealand Ministry of Education may allow for linkage to standardised service assessments to provide additional analyses of the quality of care.

A further aim of this research was to understand parents' intentions to utilise '20 Hours ECE' centre-based care in the future. This is a major policy initiative, and in particular the government is focused on increasing participation for 3- and 4-year-old Māori and Pacific children. Encouragingly, the vast majority of mothers (88 \%) were planning to use the scheme when their child was 3 or 4 years of age. Interestingly, however, $6 \%$ of mothers had not decided, and of the $6 \%$ of mothers who had decided not to utilise this scheme, almost one-third had inaccurate information about their eligibility for the scheme. These findings suggest that around $10 \%$ of the population may benefit from increased information about '20 Hours ECE' to help make an informed choice.

Our findings also highlight that intentions to use '20 Hours ECE' vary as a function of key socio-demographic factors. Pacific and Asian mothers and mothers of children cared for by family members were less likely to be planning to use this scheme. Although mothers from low-income families were also less likely, this may reflect that their existing childcare subsidies are of greater benefit. In order to achieve the current policy target, government and community initiatives to increase access to '20 Hours ECE' should focus in particular on Pacific and Asian families.

The overarching goal of the '20 Hours ECE' policy is to increase children's participation in ECE and in particular to reduce inequities in access for Māori and Pacific children and children growing up in financial hardship. Yet, implicit in this policy is the assumption that ECE participation will positively impact child outcomes. National and international evidence indicates that associations between ECE and children's cognitive and socio-emotional development are highly dependent on the quality of care and education and possibly on individual differences such as child temperament (Melhuish 2001; 
Mitchell et al. 2008; Phillips and Lowenstein 2011). While we have examined proxy indicators of quality based on maternal self-report, further research is needed that includes objective measures, potentially through direct observations or data linkage. Increasing participation in centre-based care through policy schemes such as '20 Hours ECE' is beneficial only if this increases the likelihood of children receiving high-quality care.

In particular, there is potential to enhance the utility of cohort data by linkage with other routinely collected data. Growing $U p$ has sought participant permission to link to routinely collected data during the preschool years. Consent for linkage to routinely collected health and education records has been received for approximately $97 \%$ of the cohort. To date, data linkage has been conducted with specific health data (such as discharge coding from hospitalisations, immunisation records and pharmacy data) and there is also scope to link with education data. New Zealand children have a unique identifier for the education sector once they begin primary school. The roll out of the Early Learning Information programme in New Zealand began in ECE services around the end of 2013. Therefore, consistent national enrolment data were not available for the Growing Up in New Zealand cohort to link to ECE participation. However, there is scope to link with some routinely collected demographic and quality indicators, and to link to later school records, to enhance the value of the Growing Up education findings.

We also need to consider the implications of childcare choices, and ECE policy initiatives, on children's social, emotional and cognitive outcomes. As stated by Bushouse (2008, p. 51): "what would be useful for future policy-making is a longitudinal study on the impacts of ECE participation on child outcomes". With our comprehensive measures of family functioning, child development and individual differences across time, and our potential to link to routinely collected Ministry of Education ECE data, Growing Up is ideally placed to address this issue of critical importance to policy-makers, as well as researchers and teachers.

\section{Abbreviations}

NZ: New Zealand; NZDep06: 2006 New Zealand Index of Deprivation; ECE: early childhood education.

\section{Authors' contributions}

ALB analysed and interpreted the data and completed the first and final drafts of the manuscript. PEAC developed the data collection instruments, revised the manuscript and approved the final manuscript as submitted. ER contributed to the conception and design of the study, developed the data collection instruments and completed the first and final drafts of the manuscript. SM conceived and designed the study, revised the manuscript and approved the final manuscript as submitted. All authors read and approved the final manuscript.

\section{Author details}

${ }^{1}$ Centre for Longitudinal Research-He Ara ki Mua, The University of Auckland, Auckland, New Zealand. ${ }^{2}$ Growing Up in New Zealand, The University of Auckland, Tamaki Campus, 261 Morrin Road, St Johns, Auckland 1072, New Zealand. ${ }^{3}$ Department of General Practice and Primary Health Care, The University of Auckland, Auckland, New Zealand. ${ }^{4}$ Population Studies and Demography, The University of Wakaito, Hamilton, New Zealand. ${ }^{5}$ Department of Psychology, The University of Otago, Dunedin, New Zealand.

Competing interests

The authors declare that they have no competing interests.

Received: 2 March 2016 Accepted: 27 September 2016

Published online: 06 October 2016

References

Atatoa-Carr, P. E., Reese, E., Bird, A., Bandara, D., Grant, C. C., \& Morton SMB. (submitted). (2016). Antenatal child care intention and 9-month reality: evidence from Growing Up in New Zealand. 
Bishop, R., Berryman, M., Cavanagh, T., \& Teddy, L. (2009). Te kotahitanga: addressing educational disparities facing Māori students in New Zealand. Teach Teach Educ, 25(5), 734-742.

Bushouse, B. K. (2008). Early childhood education policy in Aotearoa/New Zealand: the creation of the 20 hours free programme. A report prepared as part of an lan Axford (NZ) Fellowship in Public Policy.

Carr, M., \& May, H. (1993). Choosing a model. Reflecting on the development process of Te Whariki: National early childhood curriculum guidelines in New Zealand. Int J Early Years Educ, 1(3), 7-22.

Dalli, C. (2010). Towards the re-emergence of a critical ecology of the early childhood profession in New Zealand. Contemp Issues Early Child, 11(1), 61-74.

ERO: Education Review Office. (2015). Early childhood monographs: the quality of education and care in pacific early childhood services. http://www.ero.govt.nz/assets/Uploads/Pacific-ECE-leadership-WEB-FINAL.pdf. Accessed 1 Feb 2016.

Growing Up in New Zealand. (2014). Growing Up in New Zealand Policy Brief. Employment and parental leave around the time of birth: evidence from Growing Up in New Zealand. Auckland: Growing Up in New Zealand.

Growing Up in New Zealand. (2015). Growing Up in New Zealand Policy Brief. The intergenerational use of te reo Mãori: Evidence from Growing Up in New Zealand. Auckland: Growing Up in New Zealand.

Manning, M., Garvis, S., Fleming, C., \& Wong, G.T. (2014). Registration for a systematic review: teacher qualifications and their impact on the quality of the early childhood learning environment: a systematic review. The Campbell Collaboration

McLachlan, C. (2011). An analysis of New Zealand's changing history, policies and approaches to early childhood education. Aust J Early Child, 36(3), 36.

Melhuish, E. C. (2001). The quest for quality in early day care and preschool experience continues. Int J Behav Dev, 25(1), $1-6$

Ministry of Education. (2014a). Ministry of Education Annual Report. Wellington: Ministry of Education.

Ministry of Education. (2014b). Ministry of Education Statement of Intent. Wellington: Ministry of Education.

Mitchell, L., Wylie, C., \& Carr, M. (2008). Outcomes of early childhood education: Literature review. New Zealand Council for Educational Research.

Morton, S. M. B., Atatoa Carr, P. E., Berry, S. D., Grant, C. C., Bandara, D. K., Mohal, J., \& Tricker, P. J. (2014a). Growing Up in New Zealand: A longitudinal study of New Zealand children and their families. residential mobility report 1: moving house in the first 1000 days. Auckland: Growing Up in New Zealand

Morton, S. M. B., Atatoa Carr, P. E., Grant, C. C., Berry, S. D., Marks, E. J., Chen, X. M. H., \& Lee, A. C. (2014b). Growing Up in New Zealand: A longitudinal study of New Zealand children and their families. Vulnerability report 1: exploring the definition of vulnerability for children in their first 1000 days. Auckland: Growing Up in New Zealand.

Morton, S. M. B., Atatoa Carr, P. E., Grant, C. C., Berry, S. D., Mohal, J., \& Pillai, A. (2015). Growing Up in New Zealand: A longitudinal study of New Zealand children and their families. Vulnerability report 2: transitions in exposure to vulnerability in the first 1000 days of life. Auckland: Growing Up in New Zealand

Morton, S. M., Atatoa Carr, P. E., Grant, C. C., Robinson, E. M., Bandara, D. K., Bird, A., et al. (2013). Cohort profile: growing up in New Zealand. Int J Epidemiol, 42(1), 65-75.

Morton, S. M., Grant, C. C., Carr, P. E. A., Robinson, E. M., Kinloch, J. M., Fleming, C. J., Kingi, T. R., Perese, L., \& Liang, R. (2012), How do you recruit and retain a prebirth cohort? Lessons learnt from Growing Up in New Zealand. Evaluation and the health professions, 0163278712462717

Morton, S., Ramke, J., Kinloch, J., Grant, C. C., Carr, P. A., Leeson, H., et al. (2015b). Growing Up in New Zealand cohort alignment with all New Zealand births. Aust N Z J Public Health, 39(1), 82-87.

Phillips, D. A., \& Lowenstein, A. E. (2011). Early care, education, and child development. Ann Rev Psychol, 62, 483-500.

Sylva, K., Melhuish, E., Sammons, P., Siraj-Blatchford, I., \& Taggart, B. (Eds.). (2010). Early childhood matters: Evidence from the effective pre-school and primary education project. London: Routledge.

\section{Submit your manuscript to a SpringerOpen ${ }^{\circ}$ journal and benefit from:}

- Convenient online submission

- Rigorous peer review

- Immediate publication on acceptance

- Open access: articles freely available online

- High visibility within the field

- Retaining the copyright to your article 